\title{
Inflammation and deformity and its relation to the type of pain in rheumatoid hands: Cross sectional study
}

\author{
Bárbara Liliane Lôbo Queiroz ${ }^{1}$, Selena Márcia Dubois Mendes², Abrahão Fontes Baptista ${ }^{3}$ and Katia Nunes Sá ${ }^{4 *}$ \\ ${ }^{1}$ Physiotherapist, MSC Student of Technology Program in Health of Bahia School of Medicine and Public Health (EBMSP), Brazil \\ ${ }^{2}$ Physicotherapist, MSC in Medicine and Human Health, Doctoral Program Student in Medicine and Health of Federal University of Bahia (UFBA), Assistant \\ Professor of Bahiana School of Medicine and Public Health (EBMSP), Brazil \\ ${ }^{3}$ Physiotherapist, MSc and PhD in Morphological Sciences (UFRJ), Associate Professor at the Federal University of Bahia (UFBA), Brazil \\ ${ }^{4}$ Physiotherapist, PhD in Medicine and Human Health (EBMSP), Associate Professor at Bahiana School of Medicine and Public Health (EBMSP) and the \\ Catholic University of Salvador (UCSAL), Brazil
}

\begin{abstract}
Background: Rheumatoid arthritis (RA) is a chronic autoimmune disorder that can cause persistent pain, joint damage and permanent deformities, especially in hands and feet bilaterally. The presence of pain in RA has been explained by activation of local nociceptors, resulting from the destruction and cell death in the articular and periarticular structures affected. However, recent studies have been suggested that neuropathic pain is common in RA.

Objective: To investigate the association between the level of inflammation and the degree of deformity to the type of pain in functional joints of the hands in individuals with RA.

Methodology: Cross-sectional study carried out in a teaching-service outpatient referral, in Salvador, Bahia, Brazil. The deformations were performed by the Larsen scale on hands radiographs of hands and wrists, the level of inflammation by means of C-reactive protein and the type of pain by the DN4 questionnaire. We used the chi-square test for statistical analysis (5\% alpha). CAAE number: 51642315.5.0000.5544. Results: The sample was composed by 95 participants with level of disease activity from moderate too high. Differences were found between neuropathic and nociceptive pain in relation to the degree of deformity to the left ( $\mathrm{p}=0.004)$ and right $(\mathrm{p}=0.039)$ wrists. The pain was made available evenly between nociceptive and neuropathic $(\mathrm{P}>0.050)$. Lower degree of deformity was associated with the presence of right wrist neuropathic pain and greater deformity condition with presence of left wrist nociceptive pain.
\end{abstract}

Conclusion: The wrist is the joint most affected by nociceptive pain. Small deformities associated with neuropathic pain while high degrees of deformity are more frequent in nociceptive pain.

\section{Introduction}

Rheumatoid arthritis (RA) is a chronic autoimmune disorder that may cause persistent pain, joint damage and, over time, permanent deformities, particularly in the hands and feet bilaterally. It is the most common inflammatory polyarthritis between collagen diseases [1]. It is estimated that around 1\% of Brazilians suffer from this disease that often leads to retirement 10 years earlier than expected, with high socioeconomic costs for those affected, their families and the whole society $[2,3]$. The joints of the upper limbs are the most affected, especially of the hands and wrists, causing inflammation (pain and edema), deformities and mobility restrictions. This framework produces loss of hand function for activities of daily living and work [1].

The presence of pain from moderate to high intensity in RA has been explained by activation of local nociceptor, resulting from the destruction and cell death in the affected joint and periarticular structures [4]. Recently, however, there was a high prevalence of neuropathic pain in patients with AR [5] that requires a deepening in scientific studies to confirm this hypothesis.

Radiological studies of the hands and wrists of persons with RA, point to a strong correlation between reducing in joint space and bone erosion with limitation of movement, which could explain the presence of nociceptive pain. Larsen classification of radiologic signs has been largely accepted to characterize erosion, joint space and decreased disease progression [6]. The radiological pattern in association with an inflammatory marker such as C-reactive protein (CRP) [7] is the protocol has been commonly used in clinical practice to monitor people with RA. The results of the X-ray and CRP direct the type and dose of drugs to control the level of activity of the disease and other therapeutic approaches, such as physical resources applied by physical therapy [8]. However, pain control in RA is not so effective, even when inflammatory markers show significant drops in their values and deformities present stable [9].

On the other hand, it is known that the chronic use of drugs [5], trapping the peripheral nerves by the deformations [10] and maladaptive plasticity of the central nervous system [11] could better

Correspondence to: Katia Nunes Sá - Sá, KN. Rua Doutor Antonio Monteiro, 228 apartment 602, Itaigara, Salvador, Bahia, Brazil, Tel: +55 (71) 98883-5057, E-mail: katia.sa@gmail.com

Key words: rheumatoid arthritis, pain, inflammation, hand deformities

Received: September 19, 2016; Accepted: October 21, 2016; Published: October 25,2016 
explain the presence of neuropathic pain in individuals with RA. It is possible that by checking association between the level of inflammation and the degree of deformity to the type of pain (neuropathic or nociceptive) in the small joints of the hands, to better understand the painful phenomenon in this disease. Therefore, this study aims to determine these associations in selected joints of rheumatoid hands, specifically the most related to the pincer movement and hold, to assist in the basis for establishing more specific and effective treatment protocols to control pain RA.

\section{Methodology}

Type of study: Cross sectional study.

Population: Individuals with Rheumatoid Arthritis registered and followed the teacher-care clinic of Bahiana School of Medicine and Public Health (ADAB), Brotas, Salvador, Bahia.

Sample calculation: With support of the Winpepi calculator for estimating compare proportions of neuropathic pain by $30 \%$ and nociceptive $70 \%$ with the degree of deformity III Larsen, resulting in the need for 48 individuals, 24 per group.

Inclusion criteria: Individuals with RA according to the American College of Rheumatology criteria, enrolled in the rheumatology service of teaching-service clinic at Bahiana School of Medicine and Public Health (ADAB), aged 18 years or older, diagnosed clinical confirmed for at least one year, blood test to confirm the diagnosis and characterization of the disease activity score (rheumatoid factor, antinuclear antibodies and C-reactive protein).

Exclusion criteria: Individuals with limited understanding of the data collection instruments, presence of chronic degenerative comorbidities that might present with pain, obtained from medical records.

Instruments: Were used the Visual Analog Scale of Pain (VAS-P), the Disease Activity Score Calculator for Rheumatoid Arthritis (DAS-28), the Douleur Neuropathique four (DN-4) and a questionnaire containing information on socio-demographic data and basic anamnesis, especially developed for this purpose, following the guidelines of the Brazilian Institute of Geography and Statistics (IBGE in Portuguese). Radiographs of the wrist and hand and pathology CRP complemented the data.

Procedures: The type of pain was evaluated using the abbreviated version of DN-4 questionnaire, which consists of seven specific questions to assess whether the pain is neuropathic or not [12]. For the assessment of the disease activity score (DAS) blood samples were collected in fasting C-reactive protein (CRP) associated with the value of the Visual Analogue Scale of Pain (VAS) and the Disease Activity Score 28 (DAS-28). The definition of the disease activity score (DAS) has been carried out through an online calculator available in http:// www.das-score.nl/das28/DAScalculators/dasculators.html site. The DAS content was defined according to four cutoff points recommended by the Brazilian Society of Rheumatology in: remission with value $<2.4$; low activity characterized by 2.5 to 3.6 ; moderate activity with the value from 3.7 to 5.5 and highly active disease values $>5.6$ [13]. The joints of the wrist, metacarpophalangeal and proximal interphalangeal the first and second fingers, right and left, were assessed by radiographs and graded by a radiologist according to Larsen scale composed of six domains: 0 - Normal Articulation, No Change, 1 - Osteoporosis and edema 2 - Space Reduction Articulate and erosion, 3 - Intense erosion, moderate Destruction, 4 - Loss of Joint Space Destruction Record and
5 - ankylosis. However, in the present study by statistical criteria, were grouped first and second areas, giving rise to Class I, third and fourth areas generating Class II, and fifth and sixth areas grouped generating Class III [6].

Data collection: A previously trained team conducted data collection from March to September 2012. Built on primary data, collection began with the assessment of fasting blood followed by radiological examination and after the application of questionnaires. The first two steps were carried out in ADAB/Brotas, and the third phase was held in a private environment for supervised physical therapists or academics who carried out the reading of the questionnaires aloud, in a standardized manner, and noted the responses provided by the participants without further explanation. Each instrument was operated by a single and same examiner.

Variables: The level of inflammation (CRP) and the degree of deformity (Larsen rating) of the selected joints were considered predictors and the type of pain (DN4 - nociceptive or neuropathic) was considered as the outcome variable.

Statistical analysis: In order to describe the quantitative characteristics of the sample were used the average and the standard deviation when the distribution was normal and median and interquartile range for non-normal distributions. To describe categorical variables, was presented the absolute number with the respective proportions. To investigate the association between the level of inflammation and degree of deformity with the type of pain we used chi-square test (X2), using SPSS version 14.0.

Ethical aspects: The research project was submitted to the Research Ethics Committee of the Bahia School of Medicine and Public Health and approved under protocol number 122/2011. In 2015, it has been updated in the Platform Brazil and received the CAAE number 51642315.5.0000.5544. Data collection was conducted from March to September 2012 and each volunteer signed a consent form clarified, according all the principles of $466 / 12$ Resolution of the CNS for research in humans.

\section{Results}

The sample participants were 102 patients from the rheumatology service of ADAB/Brotas, Salvador, Bahia, Brazil, with a confirmed diagnosis of RA. However, seven of them were not included because they had incomplete data, totaling 95 participants in the final sample. There was a predominance of the Catholic religion and married state. The most frequent social class was the C2 (meadle) and the most frequent level of education was the complete high school. Regarding to the Body Mass Index (BMI), overweight predominated (Table 1). The disease duration of these individuals had a median of 144 months (IQR = 96; 204).

The presence of pain on selected joints was noted in approximately 100 of the 180 analyzed rheumatoid hands (55.5\%). It was observed that the type of pain, nociceptive or neuropathic, was distributed evenly between the metacarpophalangeal and interphalangeal joints of first and second chirodactyl in both hands, with a slight predominance of nociceptive pain in all joints analyzed (1.88\%). Only in both wrists, there was a predominance of nociceptive pain (Figure 1).

It was also observed that 10 joints that had neuropathic pain had left wrist signals of small deformations, while 23 joints with a high degree of deformity presented nociceptive pain type. This same characteristic was observed in the right wrist, with 9 individuals with neuropathic 
Table 1. Socio-demographic characteristics, individuals with rheumatoid arthritis users an outpatient at Bahiana (ADAB), $\mathrm{n}=95$.

\begin{tabular}{|c|c|c|}
\hline $\mathrm{n}=95$ & $\mathrm{n}$ & $\%$ \\
\hline \multicolumn{3}{|l|}{ Religion } \\
\hline Catholic & 43 & 45.3 \\
\hline Evangelical & 40 & 42.1 \\
\hline Spiritist & 4 & 4,2 \\
\hline Candomblé & 1 & 1.1 \\
\hline No religion & 7 & 7.4 \\
\hline \multicolumn{3}{|l|}{ Marital Status } \\
\hline Not Married & 32 & 33.7 \\
\hline Married & 50 & 52.6 \\
\hline Separate & 6 & 6.3 \\
\hline Widower & 7 & 7.4 \\
\hline \multicolumn{3}{|l|}{ Skin Color } \\
\hline White & 11 & 11.6 \\
\hline Indian & 3 & 3.2 \\
\hline Black & 37 & 38.9 \\
\hline Brown & 44 & 46.3 \\
\hline \multicolumn{3}{|l|}{ Education } \\
\hline Illiterate / Junior High & 13 & 13.7 \\
\hline Full Primary / Junior High Gym & 20 & 21.1 \\
\hline Full Gym / College Incomplete & 19 & 20.0 \\
\hline Full High School / Some College & 34 & 35.8 \\
\hline Graduated & 9 & 9.5 \\
\hline \multicolumn{3}{|l|}{ Social Class } \\
\hline High A1 & 1 & 1.1 \\
\hline A2 & 2 & 2.1 \\
\hline B1 & 3 & 3.2 \\
\hline Midle B2 & 16 & 16.8 \\
\hline C1 & 24 & 25.3 \\
\hline C2 & 38 & 40.0 \\
\hline Low D & 9 & 9.5 \\
\hline \multicolumn{3}{|l|}{ Body Mass Index (BMI) } \\
\hline Below Normal Weight & 8 & 8.4 \\
\hline Normal Weight & 25 & 26.3 \\
\hline Overweight & 32 & 33,7 \\
\hline Obesity Class I & 21 & 22.1 \\
\hline Obesity Class II & 8 & 8.4 \\
\hline Obesity Class III & 1 & 1.1 \\
\hline
\end{tabular}

Source: Research Protocol pain and 20 with nociceptive. Other statistically significant differences in relation to other joints, or in relation to deformities and not in relation to the inflammatory level were observed. However, there is a pattern of moderate deformities in all analyzed joints and symmetrical distribution of inflammation level between high and low in the sample except the wrists (Table 2).

\section{Discussion}

This work aimed to investigate the association between the level of inflammation and the degree of deformity functional hand joints of patients with rheumatoid arthritis with the type of pain. It has found that neuropathic pain is more present in the early stages of deformity and nociceptive pain in high degrees of deformity. The level of inflammation was not associated with type of pain.

The majority of the participants of this sample reported being regular practitioner of any religious activity. It has been emphasized the influence of religious practices in the resilience in patients with chronic pain. Resilience is the ability of an individual has to deal with the disease, accepting and adapting the inherent limitations of the disease, which facilitates adherence to treatment, both medical as physical therapy [14]. The socio-cultural condition of the sample, set in a secular context that combines idiosyncratic beliefs and customs with Christian African descent, may partially explain a greater optimism to face the painful phenomenon.

The overweight observed in the sample may also have influenced the inflammatory level. It has been noted that overweight and obesity are strongly correlated with increased levels of CRP $[15,16]$. Perhaps for this reason, has not been found in smaller inflammatory levels in individuals in continuous use of anti-inflammatory steroids, since the inflammation may be due to multiple and superimposing causes.
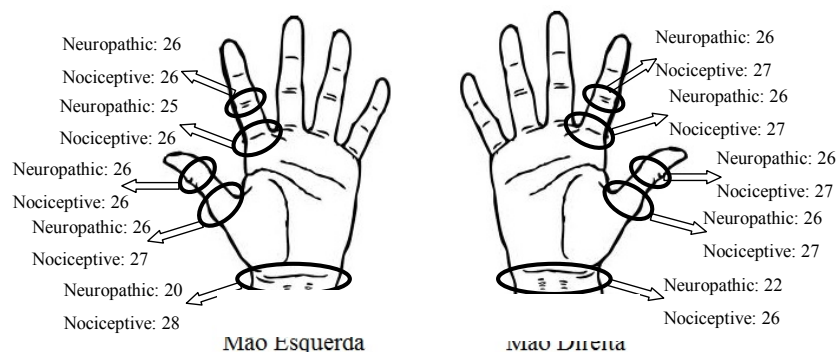

IVIau DII IIla

Figure 1. Characterization of the type of joint for pain.

Table 2. Type and degree of pain and deformity level of inflammation in patients with Rheumatoid Arthritis.

\begin{tabular}{|c|c|c|c|c|c|c|c|c|}
\hline & \multirow[b]{2}{*}{ Type of Pain } & \multicolumn{3}{|c|}{ Deformity } & & \multicolumn{2}{|c|}{ Inflammation (CRP) } & \multirow[b]{2}{*}{$\mathrm{p}$} \\
\hline & & Class I & Class II & Class III & $\mathrm{p}$ & Normal & High & \\
\hline \multirow[t]{2}{*}{ Left Wrist } & Neuropathic & 10 & 3 & 7 & \multirow[t]{2}{*}{0.004} & 11 & 9 & \multirow[t]{2}{*}{0.770} \\
\hline & Nociceptive & 4 & 1 & 23 & & 13 & 15 & \\
\hline \multirow[t]{2}{*}{ MTCF 1 Left } & Neuropathic & 4 & 16 & 6 & \multirow[t]{2}{*}{0.636} & 11 & 15 & \multirow[t]{2}{*}{0.586} \\
\hline & Nociceptive & 2 & 19 & 6 & & 14 & 13 & \\
\hline \multirow[t]{2}{*}{ MTCF 2 Left } & Neuropathic & 4 & 15 & 6 & \multirow[t]{2}{*}{0.324} & 10 & 15 & \multirow[t]{2}{*}{0.40} \\
\hline & Nociceptive & 1 & 19 & 6 & & 14 & 12 & \\
\hline \multirow[t]{2}{*}{ IF 1 Left } & Neuropathic & 3 & 13 & 10 & \multirow[t]{2}{*}{0.489} & 11 & 15 & \multirow[t]{2}{*}{0.579} \\
\hline & Nociceptive & 1 & 12 & 13 & & 14 & 12 & \\
\hline \multirow[t]{2}{*}{ IF 2 Left } & Neuropathic & 2 & 7 & 16 & \multirow[t]{2}{*}{0.234} & 10 & 15 & \multirow[t]{2}{*}{0.404} \\
\hline & Nociceptive & 0 & 11 & 15 & & 14 & 12 & \\
\hline \multirow[t]{2}{*}{ Right Wrist } & Neuropathic & 9 & 4 & 9 & \multirow[t]{2}{*}{0.039} & 13 & 9 & \multirow[t]{2}{*}{0.246} \\
\hline & Nociceptive & 4 & 2 & 20 & & 10 & 16 & \\
\hline \multirow[t]{2}{*}{ MTCF 1 Right } & Neuropathic & 1 & 20 & 5 & \multirow[t]{2}{*}{0.677} & 11 & 15 & \multirow[t]{2}{*}{0.586} \\
\hline & Nociceptive & 1 & 18 & 8 & & 14 & 13 & \\
\hline \multirow[t]{2}{*}{ MTCF 2 Right } & Neuropathic & 4 & 16 & 6 & \multirow[t]{2}{*}{0.347} & 11 & 15 & \multirow[t]{2}{*}{0.58} \\
\hline & Nociceptive & 1 & 19 & 7 & & 14 & 13 & \\
\hline \multirow[t]{2}{*}{ IF 1 Right } & Neuropathic & 2 & 17 & 7 & \multirow[t]{2}{*}{0.173} & 11 & 15 & \multirow[t]{2}{*}{0.586} \\
\hline & Nociceptive & 1 & 12 & 14 & & 14 & 13 & \\
\hline \multirow[t]{2}{*}{ IF 2 Right } & Neuropathic & 1 & 8 & 17 & \multirow[t]{2}{*}{0.476} & 11 & 15 & \multirow[t]{2}{*}{0.586} \\
\hline & Nociceptive & 0 & 11 & 16 & & 14 & 13 & \\
\hline
\end{tabular}


Future studies should observe the presence of overweight and proceed with sub-analyzes or exclude participants with this health condition, which was not feasible in this work due to the sample size.

There was predominance of nociceptive pain in the wrists. Recent studies to evaluate presence of inflammatory cytokines that act directly on the nociceptive system in patients with RA can explain this data [17]. Although individuals with RA describe their pain with nociceptive characteristics, a significant proportion of subjects reported hypersensitivity to mechanical and thermal stimuli, burning, prickling and pain, which are characteristics of neuropathic pain, supporting the view that the pain in RA involves many mechanisms, not only the peripheral inflammation [18]. The instruments used to determine the type of pain and the level of inflammation due to the absence of specific may also not have been able to specify the type of joint pain and the level of inflammation, in individualized way.

The predominance of nociceptive pain also draws attention that perhaps the entrapment of common nerves in the wrist, which usually supports surgical interventions in rheumatoid cuffs presence of carpal tunnel syndrome signs, should be better evaluated. Because the deformity is caused by progression of RA, arthrodesis have often been required, because these individuals have reduced carpal height and pronation-supination movement. It has been suggested that arthrodesis improves stability and reduces the pain intensity [19]. Additional authors reaffirm that surgical treatment should be given only in more advanced stages of the disease and because of the failure of conservative treatment [20,21]. For subjects who refuse to perform the surgery, a new conservative treatment using injections of triamcinolone acetonide has shown significant relief of pain, especially for more advanced degrees of deformity, but was unable to prevent the progression of joint degeneration [22].

The prevalence of moderate deformities in all joints demonstrates that the duration of the disease cannot be singled out as the main factor to characterize the evolutionary course of the disease. Nor to determine directly the inflammatory level, the intensity and type of pain main functional joints of the hands. Individual psychosomatic factors may partly explain the reason for the poor response to different therapeutic approaches in RA and the difficulty of pain control in this condition, even with continued use of biological drugs [22]. Studies show that the persistence of pain and the difficulty of adherence to treatment are directly linked to psychological distress (anxiety and depression), neurophysiological interaction (neuroplasticity) and social factors (family, work, financial) [4]. It is possible that psychosocial factors most influence the signs and symptoms in RA than biological factors. Topical studies have shown that the brains of people with RA suffer significant changes like those occurring in people with emotional stress, which may explain these neurogenic mechanisms [23].

Neuropathic pain is correlated more strongly with small deformities and nociceptive pain with major wrists deformities. In the case of neuropathic pain, it is possible that joints less deformed, more often observed in the early stages of the disease, are under the influence of acute central regulatory mechanisms [24]. Neuropathic pain can arise following partial lesions of the peripheral nervous system, together with other factors such as IL-1b and TNF- $\alpha$ receptor capable of sensitizing generating ectopic activity. Thus, the nociceptors are activated by norepinephrine, beginning the pain of neuropathic type [4]. While nociceptive pain in more advanced stages of the disease may be more related to central adaptation to a chronic condition, although peripherally nociceptors can be more active by advanced deformities.
The wrist and hand movements develop fine functional grip and clamp engaged in most motor tasks of the upper member. The present study has been selected major joints involved with these movements - wrist, metacarpophalangeal of first and second fingers and interphalangeal of the first and the proximal interphalangeal of the second finger. However, contrary to what was anticipated, there was not a predominance of the type of pain both in respect of deformations. The findings of this study are still to explain the true cause of pain in RA. However, the results show that the functional movements of the wrist and hand rheumatoid feature are hampered by the presence of pain, irrespective of their type, for moderate deformities and persistent inflammatory levels. Therapeutic procedures need to be more effective in pain control that constitutes the main complaint of individuals affected by RA and prevent broad social participation of this population.

This study presents a limitation to the convenience sample that generated few people with pain in wrists and many overweight people, which may have influenced the results. Future studies should follow along the evolution of pain characteristics as deformities advances to try to determine more precisely the causes of this complex phenomenon painful in this autoimmune health condition.

Given the above, it can be concluded that the wrist is the joint most affected by nociceptive pain and minor deformities are associated with neuropathic pain type, while high levels of deformity are more frequent in the nociceptive pain type.

\section{References}

1. Adams J, Bridle C, Dosanjh S, Heine P, Lamb SE, et al. (2012) Strengthening and stretching for rheumatoid arthritis of the hand (SARAH): design of a randomised controlled trial of a hand and upper limb exercise intervention - ISRCTN89936343. BMC Musculoskelet Disord 13: 230.

2. Louzada-Junior P, Souza BDB, Toledo RA, Ciconelli RM (2007) Análise descritiva das características demográficas e clínicas de pacientes com artrite reumatóide no estado de São Paulo, Brasil. Rev Bras Reumatol 47: 84-90.

3. Costa J, Almeida A, Guerra Jr. A, Cherchiglia M, Andrade E, et al. (2014) Tratamento da artrite reumatoide no Sistema Único de Saúde, Brasil?: gastos com infliximabe em comparação com medicamentos modificadores do curso da doença sintéticos , 2003 a 2006 Treatment of rheumatoid arthritis in the Brazilian Unified National Healt. Cad Saude Pública 30: 283-295.

4. Cazzola M, Atzeni F, Boccassini L, Cassisi G, Sarzi-Puttini P. (2014) Physiopathology of pain in rheumatology. Reumatismo 66: 4-13.

5. Ahmed S, Magan T, Vargas M, Harrison A, Sofat N. (2014) Use of the painDETECT tool in rheumatoid arthritis suggests neuropathic and sensitization components in pain reporting. J Pain Res 7: 579-588.

6. Johnsson PM, Eberhardt K (2009) Hand deformities are important signs of disease severity in patients with early rheumatoid arthritis. Rheumatology (Oxford) 48: 13981401. [Crossref]

7. Mangnus L, van Steenbergen HW, Lindqvist E, Brouwer E, Reijnierse M, et al. (2015) Studies on ageing and the severity of radiographic joint damage in rheumatoid arthritis. Arthritis Res Ther 17: 222. [Crossref]

8. Mouterde G, Lukas C, Logeart I, Flipo RM, Rincheval N, et al. (2011) Predictors of radiographic progression in the ESPOIR cohort: the season of first symptoms may influence the short-term outcome in early arthritis. Ann Rheum Dis 70: 1251-1256.

9. ten Klooster PM, Veehof MM, Taal E, van Riel PLCM, van de Laar MAFJ (2007) Changes in priorities for improvement in patients with rheumatoid arthritis during 1 year of anti-tumour necrosis factor treatment. Ann Rheum Dis 66: 1485-1490.

10. Agarwal V, Singh R, Wiclaf, Chauhan S, Tahlan A, et al. (2008) A clinical, electrophysiological, and pathological study of neuropathy in rheumatoid arthritis. Clin Rheumatol 27: 841-844. [Crossref]

11. Kumru H, Albu S, Vidal J, Tormos JM (2016) Effectiveness of repetitive trancrania or peripheral magnetic stimulation in neuropathic pain. Disabil Rehabil 8288: 1-11.

12. Santos JG, Brito JO, de Andrade DC, Kaziyama VM, Ferreira KA, et al. (2010) 
Translation to Portuguese and validation of the Douleur Neuropathique 4 questionnaire. J Pain 11: 484-490. [Crossref]

13. Pinheiro G da RC (2007) Instrumentos de medida da atividade da artrite reumat??ide Por que e como empreg??-los. Rev Bras Reumatol 47: 362-365

14. Bianchini DCS, Dell' Aglio DD (2006) Resilience process in the hospitalization context: a case study. Paidéia 16: 427-436.

15. Noronha JAF, Medeiros CCM, Cardoso A da S, Gonzaga NC, Ramos AT, et al. (2013) Proteína C-reativa e sua relação com pressão arterial elevada em crianças e adolescentes com sobrepeso ou obesidade. Rev Paul Pediatr 31: 331-337.

16. Timóteo AT, Miranda F, Feliciano J, Ferreira R (2011) [Influence of anthropometric variables in C reactive protein]. Acta Med Port 24: 419-426. [Crossref]

17. Schaible HG (2014) Nociceptive neurons detect cytokines in arthritis. Arthritis Res Ther 16: 470. [Crossref]

18. Christensen AW, Rifbjerg-Madsen S, Christensen R, Dreyer L, Tillingsøe H, et al. (2016) Non-nociceptive pain in rheumatoid arthritis is frequent and affects disease activity estimation: cross-sectional data from the FRAME study. Scand J Rheumatol 9742: 1-9.
19. Pech J, Sosna A, Rybka V, Pokorný D (1996) Wrist arthrodesis in rheumatoid arthritis. A new technique using internal fixation. J Bone Joint Surg Br 78: 783-786.

20. Toma CD, Machacek P, Bitzan P, Assadian O, Trieb K, et al. (2007) Fusion of the wrist in rheumatoid arthritis: A Clinical and functional evaluation of two surgical techniques. J Bone Jt Surg - Ser B 89: 1620-1626.

21. Trieb K (2014) Arthrodesis of the wrist in rheumatoid arthritis. World J Orthop 5: 512 515. [Crossref]

22. Fukui A, Yamada H, Yoshii T (2016) Effect of Intraarticular Triamcinolone Acetonide Injection for Wrist Pain in Rheumatoid Arthritis Patients: A Statistical Investigation. $J$ Hand Surg 21: 239-245.

23. Meneses FM, Queirós FC, Montoya P, Miranda JG, Dubois-Mendes SM, et al. (2016) Patients with Rheumatoid Arthritis and Chronic Pain Display Enhanced Alpha Power Density at Rest. Front Hum Neurosci 10: 395. [Crossref]

24. Rocha AP, Kraychete DC, Lemonica L, de Carvalho LR, de Barros GA, et al. (2007) Pain: current aspects on peripheral and central sensitization. Rev Bras Anestesiol 57: 94-105. [Crossref]

Copyright: (C2016 Queiroz BLL. This is an open-access article distributed under the terms of the Creative Commons Attribution License, which permits unrestricted use, distribution, and reproduction in any medium, provided the original author and source are credited. 